\title{
Age- and Sex-Related Interactions between Insulin-Like Growth Factor-I Promoter Polymorphisms and IGF-I Levels
}

\author{
E.C. van Turenhout ${ }^{1}$, J.B. Deijen ${ }^{*, 2}$, L.L.J. Koppes ${ }^{3}$, W. van Mechelen ${ }^{4}$, J.W.R. Twisk ${ }^{4}$ and \\ M.L. Drent ${ }^{1}$
}

${ }^{I}$ Department of Internal Medicine, Section Endocrinology, VU University Medical Center, Amsterdam, The Nether-
lands; ${ }^{2}$ Department of Clinical Neuropsychology, VU University, Amsterdam, The Netherlands; ${ }^{3}$ TNO Quality of Life,
Hoofddorp, The Netherlands; ${ }^{4}$ EMGO Institute, Department of Public and Occupational Health, VU University Medical
Center, Amsterdam, The Netherlands

Abstract: The present study explored sex- and age-related interactions of IGF-I polymorphisms with IGF-I serum levels. In 2000 data on IGF-I promoter polymorphism and IGF-I level were available of 344 (mean age 36; 162 men) and 6 years later in 287 subjects (133 men). As the sample sizes of groups of subjects with IGF-I genotypes 192/192, 190/192, 192/194 and 192/196 were large enough to be analyzed, the relationship between these specific genotypes and IGF-I-level was determined. The results indicated that in women aged 36 IGF-I levels for genotype 190/192 (mean 29.24 nmol/1) were higher than those for genotypes 192/192 (mean 24.29), 192/194 (mean 24.61) and 192/196 (mean 23.93). Male IGFI levels were decreased in 2006 compared to 2000 for genotypes 192/192 (mean decline - 3.67), 192/194 (mean decline 1.61), 192/196 (mean decline - 4.18), but not for 190/192. Female IGF-I levels were decreased for genotypes $192 / 192$ (mean decline - 1.85) and 190/192 (mean decline - 4.64), but not for 192/194 and 192/196. Thus females with genotype 190/192 have higher IGF-I levels, while females with genotypes 192/194 or 192/196 and males with genotype 190/192 do not show a decline of IGF-I level.

Keywords: IGF-I polymorphisms, genotype.

\section{INTRODUCTION}

Insulin-like growth factor-I (IGF-I) is a peptide hormone that is primarily secreted by the liver and is important for growth and development throughout the body. The secretion of IGF-I is mainly induced by growth hormone. Other factors influencing the serum level of IGF-I are nutritional status, the serum level of sex steroids and insulin and liver function. The level of IGF-I reaches a peak during puberty, and declines with age. IGF-I plays an important role in the regulation of cell proliferation, differentiation and apoptosis and has acute insulin-like metabolic effects [1]. Furthermore, IGF-I levels appear to be positively correlated to muscle mass, physical condition, the ratio of high-density lipoprotein to low-density lipoprotein, bone density, oxygen consumption and overall quality of life, and negatively to body fat $[2,3]$. IGF-I levels have also been shown to have a positive correlation with cognitive functioning [4]. Low IGF-I levels are associated with an increased risk of developing cardiovascular disease and diabetes, whereas high IGF-I levels in humans are associated with an increased risk of developing cancer [5-9].

In addition to the above mentioned factors that can influence IGF-I levels, it has been estimated that up to $60 \%$ of the variability has a genetic basis $[10,11]$. A genetic determinant

*Address correspondence to this author at the Department of Clinical Neuropsychology, VU University, Van der Boechorststraat 1, 1081 BT Amsterdam, The Netherlands; Tel: +31-20-5988756; Fax:+31-20-5988971;

E-mail: jb.deijen@psy.vu.nl of the IGF-I level appears to be a polymorphism in the promoter region of the IGF-I gene, being a variable length cytosine-adenine (CA) repeat sequence, which has been investigated in the past years. The repeat lengths found previously vary from a minimum of 10 repeats to a maximum of 23 repeats $[6,12]$. The term 192 was used to signify the $19 \mathrm{CA}$ repeats (192 bp) as reported by Weber and May [13] and labeled $\mathrm{Z}$ in their initial report. Other polymerase chain reaction (PCR) product sizes ranging from 188-198 were given a number designated by the length of the CA repeat [14]. The $192 \mathrm{bp}$ allele and the 194bp allele are the most common alleles and therefore considered the wild-types $[6,9,15,16]$. Studies on the IGF-I promoter polymorphism and IGF-I level have mainly focused on the 192bp allele. Systematic reviews by Fletcher et al. [6] and by Wagner et al. [12] describe how the influence of the polymorphism on the IGF-I level has been investigated in multiple studies, with variable outcomes; the first study by Rosen et al.[14] associated the 192/192 genotype with decreased IGF-1 levels, while subsequent studies have shown an association of the 192bp allele with increased hormone levels $[9,17]$, with lower IGF-I level [18], or have found no association at all [19-22]. Furthermore, Rietveld et al. [23] found that the expected age-related decline in IGF-I levels occurred in homozygotes 192/192, but not in heterozygotes and non-carriers of the $192 \mathrm{bp}$ allele. In these studies, groups were generally compared with other groups based on the number of $192 \mathrm{bp}$ alleles present: homozygotes (192/192) vs. heterozygotes (192/_) vs. non-carriers (_/) or homozygotes vs. heterozygotes and non-carriers 
combined (192/_and __ or carriers (192/192 and 192/_) vs. non-carriers.

As the present study is aimed to explore the other genotypes as well, more specific conclusions concerning differences in IGF-I levels between genotypes may be drawn.

Genetic influence on the IGF-I level is not only interesting because IGF-I levels are associated with certain types of cancer, diabetes mellitus and ischemic heart disease [6-9], but also because these diseases have been associated with the polymorphisms in the IGF-I gene itself, although conclusions have been controversial $[6,9,12,24]$. The influence of the polymorphism on the IGF-I level may be the source of a predisposition for these diseases.

The aim of this study is to describe the occurrence of polymorphisms in the IGF-I gene and genotypes of the different alleles. In addition, the present study explores the relationship between these genotypes and the IGF-I-level as well as the age-related decline of the IGF-I level in a general sample of Dutch men and women.

\section{MATERIALS AND METHODOLOGY}

\section{Subjects}

The subjects are participants of the Amsterdam Growth and Health Longitudinal Study (AGAHLS). In 1976 this study was started with a total inclusion of 698 subjects to gain an understanding of growth, development and health of children in puberty. Data concerning health, lifestyle and psychological factors have been collected and data collection is still being continued [25]. In 2000 a number of 375 subjects with an average age of 36 years (range 34-38, SD 0.74) still participated in the study. A remaining sample of 343 subjects participated in 2006, at the average age of 42 years (range 41-46, SD 0.65). Thus, the present study allows to examine IGF-I decline across a 6-year interval. The magnitude of IGF-I change per year has been estimated to be 2.1 $\mathrm{ng} / \mathrm{ml}$ in men and $2.5 \mathrm{ng} / \mathrm{ml}$ in women aged between 40 and 50 years. The slopes summarizing the age-IGF-I relationship for two different studies appeared remarkably similar [26]. Although the estimated IGF-I decline of $12.6 \mathrm{ng} / \mathrm{ml}$ in males and $15 \mathrm{ng} / \mathrm{ml}$ in females across 6 years is moderate, the estimation appears to be so precise that this interval may still reveal structural differences between genotypes.

The distribution of the IGF-I polymorphisms in nonCaucasian subjects appears to be different than that in Caucasian subjects [6,27]. Furthermore, ethnic differences in circulating levels of IGF-I have been reported [27,28]. Therefore, the 13 subjects with a non-Caucasian ancestry were excluded.

\section{Study Procedure}

Genetic polymorphisms of the IGF-I-gene and IGF-I levels of 344 Caucasian subjects (162 men, 182 women) were determined in 2000 (Table 1). In 287 of these subjects (133 men, 154 women) a second assessment of IGF-I serum levels was done in 2006.

\section{Genotyping}

The genetic polymorphisms of the IGF-I-gene were determined as described previously [9]. In brief, DNA was isolated using standard methods. PCR was performed in a final volume of $10 \mu \mathrm{L}$ containing $10 \mathrm{ng}$ DNA, 10* Gold (Au) buffer (Perkins and Elmer), $200 \mathrm{M}$ dNTP, 30 pmol of each primer, $3 \mathrm{mM} \mathrm{MgCl2}$, $0.5 \mathrm{U}$ Ampli Tag Gold polymerase (Perkins and Elmer). The PCR program consisted of 30 cycles of $30 \mathrm{sec} 95^{\circ} \mathrm{C}, 30 \mathrm{sec} 55^{\circ} \mathrm{C}$ and $30 \mathrm{sec} 72^{\circ} \mathrm{C}$ and additionally $5 \mathrm{~min}$ of denaturation at $95^{\circ} \mathrm{C}$ before the first cycle and an extension of $10 \mathrm{~min}$. at $72^{\circ} \mathrm{C}$ after the last cycle. Forward primers were labeled with $\mathrm{FAM}^{12}$ to determine the size of the PCR products by fragment analysis (ABI-Prism genetic analyzer with Genescan 2.1 software). The Genescan $350 / 500$ Tamra was used as internal size standard within the fragment analysis [16].

\section{IGF-I Serum Levels}

IGF-I serum levels were measured using a commercially available assay (Chemiluminescent immunometric, Immulite 2500, DPC, Los Angeles, USA). The detection limit was 3.2 $\mathrm{nmol} / \mathrm{l}$. The intra and inter assay coefficient of variation were both $5 \%$ for the entire range.

\section{Data Analysis}

First, subjects with missing IGF-I values were removed. Then, IGF-I serum levels were compared between genotypes, sex and year of measurement (2000/2006). Data were analyzed using Linear Mixed Model with covariance type "unstructured" for repeated measures with Group (genotype) and Sex as independent factors and Year as repeated measurements factor [29]. Since it is known that the IGF-I level of men generally tends to be higher than that of women, sex was also included as independent factor. With respect to Group, pairwise comparisons of IGF-I levels in 2000 and those in 2006 were made separately for males and females. In addition, age-related changes in IGF-I levels were analyzed with pairwise comparisons of Year (2000/2006) for each genotype separately for males and females. All statistical tests were two-tailed. Significance level was set as alpha $<0.05$. To control for multiple testing the BenjaminiHochberg correction was applied [30]. After the removal of subjects with a non-Caucasian ancestry and subjects with missing IGF-I values, data from 344 (2000) and 287 (2006) subjects were evaluable for the Mixed Linear Models Analysis. Only groups of subjects with genotypes 192/192, $190 / 192,192 / 194$ and $192 / 196$ were found large enough to be analyzed taking sex differences into account $(n \geq 6)$. The other genotypes were analyzed as one remaining group. This group consisted of 31 males and 26 females. (males: 176/192 $(\mathrm{n}=1), 188 / 192(\mathrm{n}=7), 188 / 194(\mathrm{n}=1), 188 / 196(\mathrm{n}=2)$, $190 / 190(n=1), 190 / 194(n=4), 190 / 196(n=1) 190 / 198$ $(n=1) \quad 192 / 198(n=2), 194 / 194(n=3), 194 / 196(n=8)$; females: $176 / 194 \quad(n=1), \quad 176 / 196 \quad(n=1), 188 / 192 \quad(n=2)$, $188 / 194(\mathrm{n}=3), 188 / 196(\mathrm{n}=1), 190 / 194(\mathrm{n}=1), 190 / 196$ $(\mathrm{n}=2), 190 / 198(\mathrm{n}=1), 192 / 198 \quad(\mathrm{n}=4), 194 / 194 \quad(\mathrm{n}=5)$, 194/196 (n=4), 194/198 (n=1)).

All analyses were performed using SPSS (version 16).

\section{RESULTS}

\section{Genotypes}

Seven different alleles were present in the study sample. The 192bp allele had the highest frequency (63.9\%). A number of 303 subjects $(88.1 \%)$ were carrier of the $192 \mathrm{bp}$ allele. Of these carriers, 137 were homozygote for this allele, and 
166 heterozygote. The 194bp allele was present in 132 subjects $(38.4 \%)$ of whom 8 were homozygote and 124 were heterozygote. The other alleles were found less frequently (Table 1). The distribution of genotypes was in HardyWeinberg equilibrium $(p=0.17)$.

Thus, homozygosity for 192bp had the highest prevalence and was observed in 137 subjects $(39.8 \%)$. The combined presence of 192bp and 194bp (192/194) was the second most frequently observed genotype, followed by 192/196, 190/192, and 194/196 genotypes, respectively (Table 1).

\section{Genotypes and IGF-I Level}

Variation in IGF-I levels has been found to be associated with specific lifestyle factors. Particularly, IGF-I concentrations appeared to be inversely related to BMI and the use of postmenopausal estrogen formulations [31]. Therefore, with respect to our study sample, it is important to note that ANOVA separately performed for 2000 and 2006 in males and females indicated no difference in BMI between genotype groups. In addition, chi-square tests indicated that there was no difference in distribution of the use of oral contraceptives in 2000 and 2006 across female genotype groups (Table 2).

Linear Mixed Model Analysis with Group (genotype) and Sex as independent factors and Year (2000/2006) as repeated measurements factor indicated a significant interaction between Group, Sex and Year $(F(4,292)=2.8, P<$ $0.05)$.

To explore the meaning of this interaction, we further analyzed differences in IGF-I levels determined in 2000 separately for males and females and those determined in 2006 also separately for males and females. Finally, we analyzed changes in IGF-I levels over time separately for males and females. Mean IGF-I levels (nmol/l) \pm SD in 2000 and in 2006 in males and females with different genotypes are shown in Table 3.

\section{IGF-I Levels in 2000}

With respect to males, pairwise comparisons indicated no difference in IGF-I levels in 2000 between genotype groups. In contrast, with respect to females, pairwise comparisons showed that for females IGF-I levels in the 190/192 group (mean $=29.24)$ were significantly higher than those in the $192 / 192$ group (mean $=24.29$ ), as well as those in the $192 / 194$ group $($ mean $=24.61)$ as those in the $192 / 196$ group $($ mean $=23.93)(P=0.006, P=0.013$, and $P=0.014$ respectively) (Fig. 1). IGF-I levels of the remaining group (mean $=$ 28.42) were higher than those of the 192/192 group, as well as those of the 192/194 group, as those of the 192/196 group ( $P=0.002, P=0.007$ and $P=0.012$ respectively). All these effects were significant after application of the BenjaminiHochberg correction for multiple testing (adjusted alpha = $0.03)$.

\section{IGF-I Levels in 2006}

With respect to IGF-I levels of males in 2006 pairwise comparisons indicated that IGF-I levels in the 192/194 group $($ mean $=25.76)$ tended to be higher than those of the $192 / 192$ group (mean $=23.17(P=0.087)$. In order to be significant after application of the Benjamini-Hochberg correction $P$
Table 1. Number of Subjects (and Percentages) with Specific Genotypes

\begin{tabular}{|c|c|c|c|}
\hline Genotype & Number of Subjects (\%) & Men & Women \\
\hline $176 / 192$ & $1(0.3)$ & 1 & 0 \\
\hline 176/194 & $1(0.3)$ & 0 & 1 \\
\hline 176/196 & $1(0.3)$ & 0 & 1 \\
\hline $188 / 192$ & $9(2.6)$ & 7 & 2 \\
\hline 188/194 & $4(1.2)$ & 1 & 3 \\
\hline 188/196 & $3(0.9)$ & 2 & 1 \\
\hline $190 / 190$ & $1(0.3)$ & 1 & 0 \\
\hline 190/192 & $19(5.5)$ & 7 & 12 \\
\hline 190/194 & $5(1.4)$ & 4 & 1 \\
\hline $190 / 196$ & $3(0.9)$ & 1 & 2 \\
\hline $190 / 198$ & $2(0.6)$ & 1 & 1 \\
\hline $192 / 192$ & $137(39.8)$ & 62 & 75 \\
\hline $192 / 194$ & $101(29.3)$ & 50 & 51 \\
\hline $192 / 196$ & $30(8.7)$ & 12 & 18 \\
\hline $192 / 198$ & $6(1.7)$ & 2 & 4 \\
\hline 194/194 & $8(2.3)$ & 3 & 5 \\
\hline $194 / 196$ & $12(3.5)$ & 8 & 4 \\
\hline 194/198 & $1(0.3)$ & 0 & 1 \\
\hline total & $344(100)$ & 162 & 182 \\
\hline
\end{tabular}

should be less than the adjusted alpha $=0.005$, meaning that this finding is likely the result of chance.

With respect to females, although the pattern of IGF-I levels was similar to that of 2000 pairwise comparisons indicated no difference in IGF-I levels in 2006 between genotype groups (Fig. 1).

\section{IGF-I Level Differences between Age 36 and 42 Years}

For the whole group of subjects, irrespective of Sex and Group, a significant decline in IGF-I levels was seen between the mean age of 36 and 42 years $(P<0.0001)$. In addition, there was no significant interaction between Sex and Year, indicating that the decline was similar in males as in females.

With respect to males, pairwise comparisons indicated that after correction with Benjamini-Hochberg (adjusted alpha $=0.03)$ IGF-I levels were decreased in 2006 compared to 2000 in subjects with genotypes 192/192 (mean decline $3.67 \mathrm{nmol} / \mathrm{l}, P<0.0001$ ), $192 / 194$ (mean decline -1.61 nmol/1, $P=0.005$ ), $192 / 196$ (mean decline $-4.18 \mathrm{nmol} / 1 \mathrm{P}=$ 0.02 ), and were neither decreased in genotype $190 / 192$ nor in the remaining group.

With respect to females, after correction with BenjaminiHochberg (adjusted alpha $=0.03$ ) IGF-I levels were significantly decreased in 2006 compared to 2000 in subjects with 
genotypes $192 / 192$ (mean decline $-1.85 \mathrm{nmol} / \mathrm{l}, P=0.002$ ), $190 / 192$ (mean decline $-4.64 \mathrm{nmol} / \mathrm{l}, P=0.008$ ) and in subjects from the remaining group (mean decline $-3.58 \mathrm{nmol} / \mathrm{l}$, $P<0.0001$ ), but not in $192 / 194$ and $192 / 196$.

\section{DISCUSSION}

This explorative study describes the distribution of the IGF-I promoter polymorphisms and examines the relationship between IGF-I promoter genotype and IGF-I level. The repeat lengths found previously vary from a minimum of 10 repeats to a maximum of 23 repeats $[6,12]$. As a consequence it is theoretically possible to find 14 different alleles. In our study sample consisting of Caucausion subjects seven different alleles were present. Mainly the 192bp and 194bp alleles were present in our sample. The allele frequency of the $192 \mathrm{bp}$ allele was $63.9 \%$, which corresponds to the allele frequency reported in other Caucasian populations, estimated to be between 59\% [14] and 70\% [20]. In line with former reports, the allele frequency we found for the 194bp allele was $20.2 \%$ [9,14,20]. Although the occurrence of the other genotypes has been determined in other studies, they are most often referred to as 'others'. In agreement with findings of studies reported previously, homozygosity for 192bp had highest prevalence $39.8 \%$ ) $[9,14,23,32]$ and heterozygotes $192 / 194$ were observed in $29.3 \%$ [14]. We, however, have described the occurrence and the relationships with IGF-I levels of the other genotypes more specifically. In the present study also a remaining group was included in the analyses. As this group consisted of such a heterogeneous variety of genotypes with low frequencies, we considered it useless to take the results into account and therefore leave these out of the discussion.

With respect to females, we found significantly higher IGF-I levels for the $190 / 192$ group compared to the $192 / 192$, the 192/194 and the 192/196 genotypes. In studies that divided subjects into 'carriers' and 'non-carriers' of the $192 \mathrm{bp}$ allele, subjects with the 190/192 genotype were in the same group as subjects with 192/192 and 192/196 genotypes $[20,27,33]$. As a consequence, the comparison between carriers and non-carriers lacks specificity. In the same way the comparison of 'homozygotes' vs. 'heterozygotes and noncarriers' in other studies is not specific. Thus, in contrast to former studies we were able to show that the IGF-I level of the 190/192 genotypes in females was higher than that of other genotypes.

The mean IGF-I levels found in our study were in the normal range (in both men and in women, aged $36-40$ years: $11.2-35.7 \mathrm{nmol} / \mathrm{l}\left(\mathrm{P}_{5}-\mathrm{P}_{95}\right)$; in men and women aged 41-51 years: $\left.9.7-28.8 \mathrm{nmol} / 1\left(\mathrm{P}_{5}-\mathrm{P}_{95}\right)\right)$. Our results suggest that heterozygotes 190/192 in females had higher IGF-I levels than others. Therefore, differences in bone mineral density, body composition, lipid profile and brain functioning are likely to differ between genotypes, and between men and women. Moreover, several studies have investigated the relationship between the IGF-I promoter polymorphism and risk of specific disorders, e.g. breast cancer, bone mineral density, colorectal cancer, hereditary non-polyposis colorectal cancer, prostate cancer, type 2 diabetes, cardiovascular disease and polycystic ovary syndrome $[7,9,12]$. Most of these studies focused on the 192bp allele. Considering the results of the present study, it is more revealing to focus in females on the 190/192 genotype while examining the effect of the IGF-I promoter polymorphism on various disorders.

It has been postulated that decreasing levels of IGF-I may be partly responsible for effects of aging, as these are similar to IGF-I deficiency [2,34-37]. With respect to the expected decrease in IGF-I levels from 2000 to 2006 we found a reduction in IGF-I levels from 2000 to 2006 with respect to all four genotypes when sex was not taken into account. However, IGF-I decline appeared to be sex-specific as no significant decrease was found in males with genotype 190/192 and in females with genotypes 192/194 and 192/196. Rietveld et al. [23] found an age-related decline in IGF-I levels in homozygotes 192/192 but not in heterozygotes and non-carriers of the $192 \mathrm{bp}$ allele. There was no distinction made between males and females. With respect to females our results are similar, noting that due to infrequent occurrence no noncarriers of the $192 \mathrm{bp}$ allele were evaluated in our study. Rietveld et al. suggested that the IGF-I levels in heterozygotes and non-carriers are less growth hormone-dependent and more influenced by other factors such as liver function, nutrition and insulin levels, and show therefore no decline along with the growth hormone levels. In our study growth hormone levels were not measured and further studies are needed to test this hypothesis.

Table 2. Mean BMI Values $\left(\mathrm{kg} / \mathrm{m}^{2}\right) \pm$ SD and Number (and Percentage) of Oral Contraceptive Users within different Genotype Groups

\begin{tabular}{|c|c|c|c|c|c|c|}
\hline \multirow[t]{2}{*}{ Genotype } & \multirow{2}{*}{$\begin{array}{c}\text { Male } \\
\text { BMI }\end{array}$} & \multicolumn{2}{|c|}{ Female } & \multirow{2}{*}{$\begin{array}{c}\text { Male } \\
\text { BMI }\end{array}$} & \multicolumn{2}{|c|}{ Female } \\
\hline & & BMI & $\mathrm{OC}$ & & BMI & $\mathrm{OC}$ \\
\hline $192 / 192$ & $24.2 \pm 2.8$ & $23.5 \pm 3.7$ & $33(44)$ & $24.6 \pm 2.8$ & $24.2 \pm 4.2$ & $25(33)$ \\
\hline $192 / 194$ & $25.5 \pm 2.5$ & $23.0 \pm 3.0$ & $13(25)$ & $26.0 \pm 3.0$ & $23.5 \pm 3.1$ & $7(14)$ \\
\hline $192 / 196$ & $25.2 \pm 2.3$ & $23.2 \pm 2.9$ & 7 (39) & $25.2 \pm 3.2$ & $23.8 \pm 3.4$ & $2(11)$ \\
\hline other & $24.3 \pm 2.7$ & $23.6 \pm 2.9$ & $6(46)$ & $24.4 \pm 2.7$ & $24.7 \pm 3.1$ & $5(38)$ \\
\hline
\end{tabular}


Table 3. Mean IGF-I Levels (nmol/l) \pm SD in 2000 and in 2006 in Males and Females with different Genotypes

\begin{tabular}{|c|c|c|c|c|}
\hline & \multicolumn{2}{|c|}{ 2000 } & 2006 \\
\hline Genotype & Male (n) & Female (n) & Male (n) & Female (n) \\
\hline \hline $192 / 192$ & $26.84 \pm 5.31(62)$ & $24.29 \pm 5.96(75)$ & $23.17 \pm 4.96(49)^{\downarrow}$ & $22.44 \pm 5.70(66)^{\downarrow}$ \\
\hline $190 / 192$ & $24.74 \pm 5.42(7)$ & $29.24 \pm 7.57(12)^{*}$ & $22.63 \pm 5.77(7)$ & $24.60 \pm 7.41(10)^{\downarrow}$ \\
\hline $192 / 194$ & $27.37 \pm 6.0(50)$ & $24.61 \pm 5.50(51)$ & $25.76 \pm 5.61(44)^{\downarrow}$ & $23.55 \pm 4.70(41)$ \\
\hline $192 / 196$ & $27.35 \pm 3.90(12)$ & $23.93 \pm 3.99(18)$ & $23.17 \pm 4.61(8)^{\downarrow}$ & $23.38 \pm 4.05(15)$ \\
\hline other & $25.89 \pm 6.0(31)$ & $28.42 \pm 6.92(26)^{*}$ & $24.94 \pm 6.19(25)$ & $24.84 \pm 5.73(22)^{\downarrow}$ \\
\hline All & $26.77 \pm 5.55(162)$ & $25.26 \pm 6.14(182)$ & $24.33 \pm 5.50(133)^{\downarrow}$ & $23.31 \pm 5.44(154)^{\downarrow}$ \\
\hline
\end{tabular}

$* P \leq 0.01$ vs female genotypes $192 / 192,192 / 194,192 / 196 \quad$ ' $P<0.03$ vs 2000

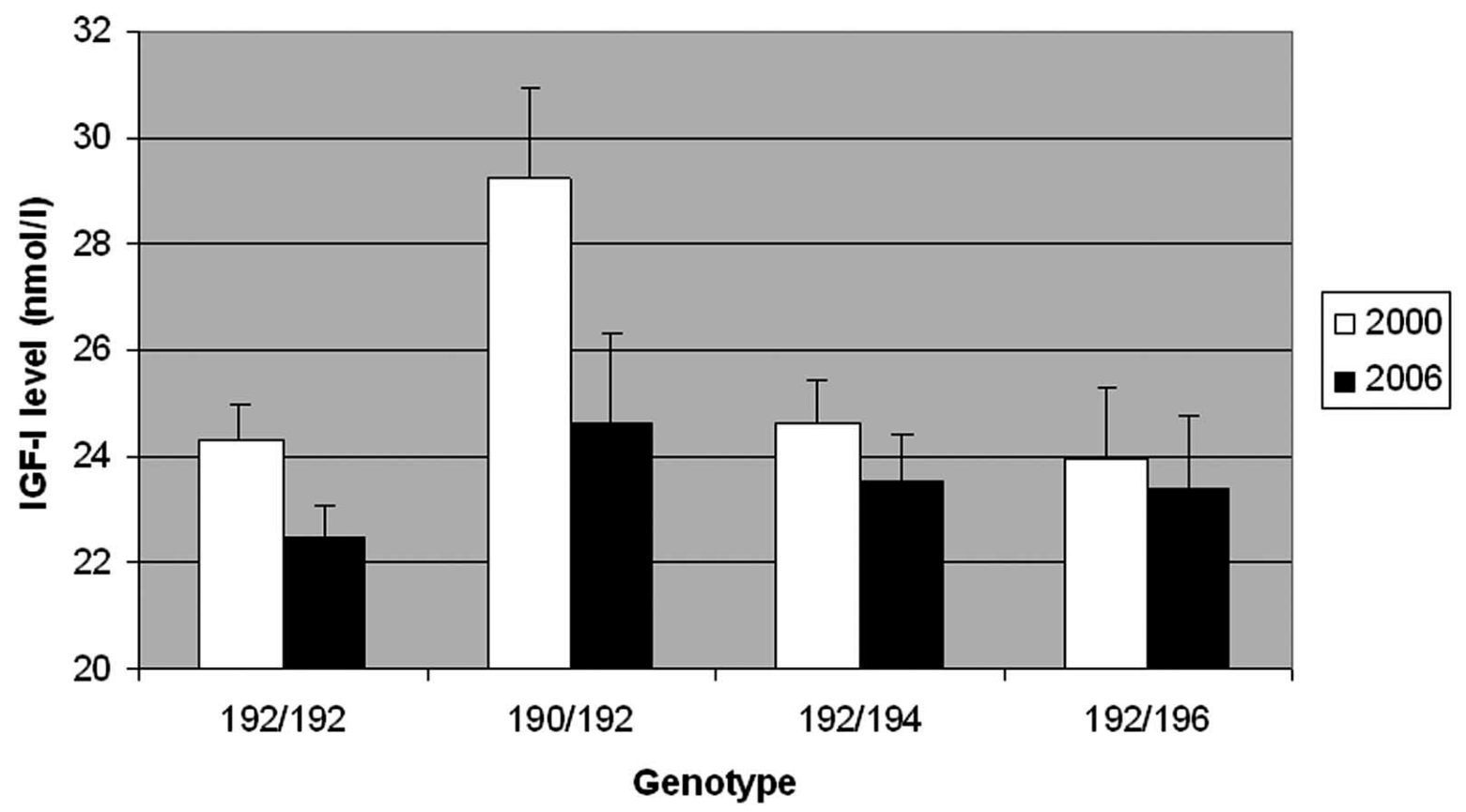

Fig. (1). Mean IGF-I levels (nmol/l) \pm SD in 2000 and in 2006 in females with different genotypes.

Our results suggest that IGF-I levels are influenced by IGF-I polymorphisms. Yet, the mechanism through which the IGF-I polymorphism influences the IGF-I level is still unclear. It may affect transcription or it may be in linkage disequilibrium with another functional variant. Although there are no regulatory elements close to the repeat region, it has been shown that CA elements are able to form unusual DNA conformations, such as Z-forms, that may modulate transcriptional activity [38]. Furthermore, since the replication fork pauses at the repeats with an increasing repeat length, the DNA becomes more unstable and is more prone to involve slippage events or doublestrand breaks [12,39].

It is important to note that the method used in the present study to determine genetic polymorphisms of the IGF-I-gene may have introduced errors in the classification of genotype. In a small case-control study comparing sizing analysis with direct DNA sequencing in analyzing CA repeats in the IGF-I gene a substantial discrepancy between the methods in de- termining homozygous alleles was found. From this observed discrepancy the authors conclude that although DNA sizing analysis is the method of choice in analyzing short tandem repeat (STR) polymorphisms, laboratory analysis of dinucleotide STR may be unreliable in detecting small allelic differences [40]. Thus, our study results should be interpreted cautiously.

In addition, other polymorphisms in the IGF-I gene may contribute to IGF-I levels. Recently, data have been published on Single Nucleotide Polymorphisms (SNPs) within the IGF-I locus, or within evolutionarily conserved noncoding regions (ECRs) close to the IGF-I locus. Different SNPs, significantly associated with IGF-I levels have been found: rs35767 [41-43], rs6220 [41,44,45], rs1520220 [4446] rs35765 [41], rs5742678, rs5742694 and rs2946834 [44], rs7965399 [43] and rs6214, rs5742612, rs5742614, rs5742657, rs5742692, and rs3730204 [46]. Others found no significant associations between IGF-I tag SNPs and circulating 
levels of IGF-I [47]. In this study we have not taken the possible influence of these polymorphisms on the IGF-I levels into account.

In conclusion, our population-based 6-year longitudinal study with Caucasian men and women studied at average ages of 36 and 42 years suggests that a genetic polymorphism in the promoter region of the IGF-I gene interacts with both sex and age in its IGF-I expression. In the general Caucasian population, the presence of the 190/192 genotype in females (as observed in $6.6 \%$ of women) seems associated with higher IGF-I levels. Furthermore, no age-related decline of the IGF-I levels was observed in males with genotype 190/192 and in females with genotypes 192/194 and 192/196. This may have consequences for tissues and metabolic factors on which IGF-I acts, e.g. for bone, lipids and brain. Further studies are needed to clarify the clinical implications of the observed genotype-related differences in (decline of) IGF-I levels.

\section{REFERENCES}

[1] Froesch ER, Zapf J. Insulin-like growth factors and insulin: comparative aspects. Diabetologia 1985; 28: 485-93.

[2] Arwert LI, Deijen JB, Drent ML. The relation between insulin-like growth factor I levels and cognition in healthy elderly: a metaanalysis. Growth Horm IGF Res 2005; 15: 416-22.

[3] Becker AJ, Uckert S, Stief CG, Jonas U. Growth hormone, somatomedins and men's health. Aging Male 2002; 5: 258-62.

[4] Arwert LI, Roos JC, Lips P, Twisk JW, Manoliu RA, Drent ML. Effects of 10 years of growth hormone $(\mathrm{GH})$ replacement therapy in adult GH-deficient men. Clin Endocrinol (Oxf) 2005; 63: 31016.

[5] Chen W, Wang S, Tian T, et al. Phenotypes and genotypes of insulin-like growth factor 1, IGF-binding protein-3 and cancer risk: evidence from 96 studies. Eur J Hum Genet 2009; 17: 1668-75.

[6] Fletcher O, Gibson L, Johnson N, et al. Polymorphisms and circulating levels in the insulin-like growth factor system and risk of breast cancer: a systematic review. Cancer Epidemiol Biomarkers Prev 2005; 14: 2-19.

[7] Janssen JA, Lamberts SW. Igf-I and longevity. Horm Res 2004;62 Suppl 3:104-9.

[8] Renehan AG, Zwahlen M, Minder C, O'Dwyer ST, Shalet SM, Egger M. Insulin-like growth factor (IGF)-I, IGF binding protein-3, and cancer risk: systematic review and meta-regression analysis. Lancet 2004; 363: 1346-53.

[9] Vaessen N, Heutink P, Janssen JA, et al. A polymorphism in the gene for IGF-I: functional properties and risk for type 2 diabetes and myocardial infarction. Diabetes 2001; 50: 637-42.

[10] Harrela M, Koistinen H, Kaprio J, et al. Genetic and environmental components of interindividual variation in circulating levels of IGF-I, IGF-II, IGFBP-1, and IGFBP-3. J Clin Invest 1996; 98: 2612-15.

[11] Hong Y, Pedersen NL, Brismar K, Hall K, de FU. Quantitative genetic analyses of insulin-like growth factor I (IGF-I), IGFbinding protein-1, and insulin levels in middle-aged and elderly twins. J Clin Endocrinol Metab 1996; 81: 1791-97.

[12] Wagner K, Hemminki K, Forsti A. The GH1/IGF-1 axis polymorphisms and their impact on breast cancer development. Breast Cancer Res Treat 2007; 104: 233-48.

[13] Weber JL, May PE. Abundant class of human DNA polymorphisms which can be typed using the polymerase chain reaction. Am J Hum Genet 1989; 44: 388-96.

[14] Rosen CJ, Kurland ES, Vereault D, et al. Association between serum insulin growth factor-I (IGF-I) and a simple sequence repeat in IGF-I gene: implications for genetic studies of bone mineral density. J Clin Endocrinol Metab 1998; 83: 2286-90.

[15] Rietveld I, Ikram MK, Vingerling JR, et al. An igf-I gene polymorphism modifies the risk of diabetic retinopathy. Diabetes 2006; 55: 2387-91.

[16] te Velde SJ, van Rossum EF, Voorhoeve PG, et al. An IGF-I promoter polymorphism modifies the relationships between birth weight and risk factors for cardiovascular disease and diabetes at age 36. BMC Endocr Disord 2005;5:5.

[17] Missmer SA, Haiman CA, Hunter DJ, et al. A sequence repeat in the insulin-like growth factor-1 gene and risk of breast cancer. Int J Cancer 2002; 100: 332-6.

[18] Frayling TM, Hattersley AT, McCarthy A, et al. A putative functional polymorphism in the IGF-I gene: association studies with type 2 diabetes, adult height, glucose tolerance, and fetal growth in U.K. populations. Diabetes 2002; 51:2313-6.

[19] Giovannucci E, Haiman CA, Platz EA, Hankinson SE, Pollak MN, Hunter DJ. Dinucleotide repeat in the insulin-like growth factor-I gene is not related to risk of colorectal adenoma. Cancer Epidemiol Biomarkers Prev 2002; 11: 1509-10.

[20] Jernström H, Deal C, Wilkin F, et al. Genetic and nongenetic factors associated with variation of plasma levels of insulin-like growth factor-I and insulin-like growth factor-binding protein-3 in healthy premenopausal women. Cancer Epidemiol Biomarkers Prev 2001; 10: 377-84.

[21] Kato I, Eastham J, Li B, Smith M, Yu H. Genotype-phenotype analysis for the polymorphic CA repeat in the insulin-like growth factor-I (IGF-I) gene. Eur J Epidemiol 2003;18: 203-9.

[22] Wen W, Gao YT, Shu XO, et al. Insulin-like growth factor-I gene polymorphism and breast cancer risk in Chinese women. Int J Cancer 2005; 113: 307-11.

[23] Rietveld I, Janssen JA, Hofman A, Pols HA, van Duijn CM, Lamberts SW. A polymorphism in the IGF-I gene influences the agerelated decline in circulating total IGF-I levels. Eur J Endocrinol 2003; 148: 171-5.

[24] Chen X, Guan J, Song Y, et al. IGF -I (CA) repeat polymorphisms and risk of cancer: a meta-analysis. J Hum Genet 2008; 53:227-38.

[25] Kemper HC. Amsterdam Growth and Health Longitudinal Study (AGAHLS); a 23-Year Follow-up from Teenager to Adult about Lifestyle and Health. Medicine and Sport Science Basel: Karger; 2004; Vol. 47.

[26] Maggio M, Ble A, Ceda GP, Metter, EJ. Decline in Insulin-like growth factor-I levels across adult life span in two large population studies. J Gerontol A Biol Sci Med Sci 2006; 61: 182-3.

[27] Jernström H, Chu W, Vesprini D, et al. Genetic factors related to racial variation in plasma levels of insulin-like growth factor-1: implications for premenopausal breast cancer risk. Mol Genet Metab 2001; 72: 144-54.

[28] Platz EA, Pollak MN, Rimm EB, et al. Racial variation in insulinlike growth factor- 1 and binding protein- 3 concentrations in middle-aged men. Cancer Epidemiol Biomarkers Prev 1999; 8: 110710.

[29] Cnaan A, Laird NM, Slasor P. Using the general linear mixed model to analyse unbalanced repeated measures and longitudinal data. Stat Med 1997; 16: 2349-80.

[30] Benjamini Y, Hochberg, Y. Controlling the false discovery rate: a practical and powerful approach to multiple testing. J R Stat Soc B 1995; 57: 289-300.

[31] Morimoto LM, Newcomb PA, White E, Bigler J, Potter JD. Variation in plasma insulin-like growth factor-1 and insulin-like growth factor binding protein-3: personal and lifestyle factors (United States). Cancer Causes Control 2005; 16: 917-27.

[32] Cleveland RJ, Gammon MD, Edmiston SN, et al. IGF1 CA repeat polymorphisms, lifestyle factors and breast cancer risk in the Long Island Breast Cancer Study Project. Carcinogenesis 2006; 27: 75865.

[33] Allen NE, Davey GK, Key TJ, Zhang S, Narod SA. Serum insulinlike growth factor I (IGF-I) concentration in men is not associated with the cytosine-adenosine repeat polymorphism of the IGF-I gene. Cancer Epidemiol Biomarkers Prev 2002; 11: 319-20.

[34] Capri M, Salvioli S, Sevini F, et al. The genetics of human longevity. Ann N Y Acad Sci 2006; 1067: 252-63.

[35] Ceda GP, Dall'Aglio E, Maggio M, et al. Clinical implications of the reduced activity of the GH-IGF-I axis in older men. J Endocrinol Invest 2005; 28(11 Suppl Proceedings): 96-100.

[36] Corpas E, Harman SM, Blackman MR. Human growth hormone and human aging. Endocr Rev 1993; 14: 20-39.

[37] van Dam PS, Aleman A. Insulin-like growth factor-I, cognition and brain aging. Eur J Pharmacol 2004; 490: 87-95.

[38] Peters DG, Kassam A, St Jean PL, Yonas H, Ferrell RE. Functional polymorphism in the matrix metalloproteinase- 9 promoter as a potential risk factor for intracranial aneurysm. Stroke 1999; 30: 2612-2616. 
[39] Pearson CE, Nichol EK, Cleary JD. Repeat instability: mechanisms of dynamic mutations. Nat Rev Genet 2005; 6: 729-42.

[40] Tran N, Bharaj BS, Diamandis EP, Smith M, Li BD, Yu H. Short tandem repeat polymorphism and cancer risk: influence of laboratory analysis on epidemiologic findings.Cancer Epidemiol Biomarkers Prev 2004;13: 2133-40.

[41] Canzian F, McKay JD, Cleveland RJ, et al. Polymorphisms of genes coding for insulin-like growth factor I and its major binding proteins, circulating levels of IGF-I and IGFBP- 3 and breast cancer risk: results from the EPIC study. Br J Cancer 2006; 94: 299-307.

[42] Palles C, Johnson N, Coupland B, et al. Identification of genetic variants that influence circulating IGF1 levels: a targeted search strategy. Hum Mol Genet 2008; 17: 1457-64.

[43] Patel AV, Cheng I, Canzian F, et al. Breast and Prostate Cancer Cohort Consortium. IGF-1, IGFBP-1, and IGFBP-3 polymorphisms predict circulating IGF levels but not breast cancer risk: findings from the Breast and Prostate Cancer Cohort Consortium (BPC3). PLoS One 2008; 3(7): e2578.
[44] Al-Zahrani A, Sandhu MS, Luben RN, et al. IGF1 and IGFBP3 tagging polymorphisms are associated with circulating levels of IGF1, IGFBP3 and risk of breast cancer. Hum Mol Genet 2006; 15 $1-10$.

[45] Diorio C, Brisson J, Bérubé S, Pollak M. Genetic polymorphisms involved in insulin-like growth factor (IGF) pathway in relation to mammographic breast density and IGF levels. Cancer Epidemiol Biomarkers Prev 2008; 17: 880-8.

[46] D'Aloisio AA, Schroeder JC, North KE, et al. IGF-I and IGFBP-3 polymorphisms in relation to circulating levels among African American and Caucasian women. Cancer Epidemiol Biomarkers Prev 2009; 18: 954-66.

[47] Cheng I, DeLellis Henderson K, Haiman CA, et al. Genetic determinants of circulating insulin-like growth factor (IGF)-I, IGF binding protein (BP)-1, and IGFBP-3 levels in a multiethnic population. J Clin Endocrinol Metab 2007; 92: 3660-6.

(C) van Turenhout et al.; Licensee Bentham Open.

This is an open access article licensed under the terms of the Creative Commons Attribution Non-Commercial License (http://creativecommons.org/licenses/by-nc/3.0/) which permits unrestricted, non-commercial use, distribution and reproduction in any medium, provided the work is properly cited. 